\title{
Effects of an intensive slow cortical potentials neurofeedback training in female and male adolescents with autism spectrum disorder
}

\section{Are there sex differences?}

\author{
Sonja G. Werneck-Rohrer (D) - Theresa M. Lindorfer • Carolin Waleew • Julia Philipp - Karin Prillinger • \\ Lilian Konicar
}

Received: 12 October 2021 / Accepted: 16 November 2021 / Published online: 15 December 2021

(C) The Author(s) 2021

\begin{abstract}
Summary
Background This study aims to compare the effects of neurofeedback training on male and female adolescents with autism spectrum disorder (ASD). Furthermore, it examines sex differences regarding improvements in co-occurring psychopathological symptoms, cognitive flexibility and emotion recognition abilities. The study might provide first hints whether there is an influence of sex on treatment outcomes.

Methods Six female and six male adolescents with ASD were matched according to age, IQ and symptom severity. All participants received 24 sessions of electroencephalography-based neurofeedback training. Before and after the intervention, psychological data for measuring co-occurring psychopathological symptoms as well as behavioral data for measuring cognitive flexibility and emotion recognition abilities were recorded.

Results Caregivers rated statistically significant higher psychopathological problems in female than in male adolescents with ASD at baseline. Apart from that, no statistically significant sex-related differences were revealed in this sample; however, male adolescents tended to report greater improvements of externalizing, internalizing and total symptoms, whereas females experienced smaller improvements of externalizing and total problems, but no improvements of internalizing problems. Regarding caregivers' assessments, more improvement of total problems was re-
\end{abstract}

\footnotetext{
Mag. Dr. S. G. Werneck-Rohrer ( $\bowtie) \cdot$ T. M. Lindorfer •

C. Waleew $\cdot$ J. Philipp $\cdot$ K. Prillinger $\cdot$ L. Konicar

Department of Child and Adolescent Psychiatry. Währinger

Gürtel 18-20, Medical University of Vienna, 1090 Vienna,

Austria

sonja.werneck-rohrer@meduniwien.ac.at
}

ported for females. For males, only improvements of internalizing and total problems were described.

Conclusion This study reveals preliminary results that sex-related differences might play a role when evaluating treatment outcomes after neurofeedback training regarding comorbid psychopathological symptoms. Adolescents' self-report and parental assessments, especially concerning psychopathological symptoms, should be combined and considered in future studies to help prevent sex bias in adolescents with ASD.

Keywords Female ASD - Neurofeedback therapy · Comorbid psychopathological symptoms of ASD . Cognitive flexibility $\cdot$ Emotion recognition

\section{Introduction}

Autism spectrum disorder (ASD) is generally described as a neurodevelopmental disorder characterized by impairments in reciprocal social interaction, a deficit in social communication, repetitive and restrictive behavior [1]. In recent years, the prevalence of ASD has increased due to improved diagnostic criteria and greater awareness of ASD symptoms; however, there is a lack of research on ASD in women, as scientific studies predominantly included male subjects [2, 3]. In females ASD is often unrecognized, undiagnosed or misdiagnosed due to a different phenotype presentation in females and a lack of sexspecific elements in diagnostic procedures [2]. This fact can lead to a shortage of interventions specifically targeting the impairments of females with ASD. There are different theses that defend the hypothesis of a rarer occurrence of ASD in females. One is the female protective effect, which states that women require a higher genetic and/or environmental risk 
to be affected by it than men, meaning that sex can be a protective factor. Another theory is the extreme male brain theory. This states that the male brain is defined as thinking systematically and having less empathy, whereas the female brain is defined with the opposite characteristics. Therefore, ASD would be an extreme expression of a typically male brain [3]; however, the female camouflage effect is probably one of the most interesting explanatory approaches to understand the underdiagnosis of ASD in females. It posits that females with ASD often try to compensate and hide their social difficulties from others [4, 5]. In general, girls with ASD show a great desire to establish interpersonal relationships, want to fit in and aim to avoid negative judgements and reactions from society [6]. A study by Cola and colleagues [7] showed that after speaking to persons who did not know the diagnosis, the social abilities of girls with ASD were rated more typical than those of boys with ASD. This investigation exemplified that recognizing ASD symptoms is apparently more difficult in girls than in boys [3].

Loomes and colleagues [8] reported that the male to female ratio in ASD is not 4:1 (as assumed in the diagnostic and statistical manual of mental disorders, fifth edition, DSM-5 [9]) but rather 3:1, as females with ASD are at a disproportional risk of not being diagnosed. This comes partly from diagnostic measures, which barely include female characteristics of ASD [10, 11] or diverging sex-related clinical presentations of ASD. In early childhood for example, more depressive and anxious behavior was seen in girls with ASD and more restricted, repetitive and stereotyped behavior in boys with ASD [12, 13]. Interestingly, while in the categories of circumscribed interests and unusual preoccupations $[14,15]$ sex-related differences in ASD were found, no differences were found in the total scores of the autism diagnostic interview (ADI-R [16]) and the ADI-R subscale restrictive and repetitive behavior.

Therefore, it is crucial to consider that a solely male understanding of ASD lowers the probability of detecting ASD in females [17, 18], leading to belated diagnoses and treatment delay [17-20], yielding sex biasbased problems in health, identity and well-being of females with ASD [21].

\section{Deficits in executive functions and emotion processing in ASD}

Besides information updating and inhibition control, cognitive flexibility is a major part of executive functioning [22] and assumed to be impaired in patients with ASD [23]. Willcut et al. [24] found strong effect sizes for differences in cognitive flexibility between patients with ASD and typically developing subjects; however, meta-analysis yielded controversial results [25]. Thus, cognitive flexibility tasks may be difficult for patients with ASD for other reasons, such as learning through feedback and performance clearly depends on the type of tasks and on the task instructions [23, 26]. Hull et al. [27] further described sex differences in performance on cognitive flexibility tasks depending on the type of task; for example, no differences are shown on the Wisconsin card sorting test, while performance on the Trail Making Test was better in females than in males. A functional magnetic resonance imaging (fMRI) study by Shafritz et al. [28] reported lower activation in the frontal, striatal, and parietal regions of the brain, parallel to seemingly different task solving strategies of typically developing subjects and patients with ASD.

Regarding attention deficit hyperactivity disorder (ADHD), a common comorbidity of ASD, much more research was conducted to investigate sex differences. For example, differences in processing speed and working memory between female and male patients with ADHD were reported [29]. Furthermore, a metaanalysis showed more hyperactive behavior, more deficits in motor response inhibition and cognitive flexibility in boys with ADHD than in girls with ADHD [30]. As the symptomatology of ASD and ADHD often appear together, similar sex differences might be found in ASD in future studies.

Regarding emotional processing, the most common finding is an impairment in facial emotion recognition in individuals with ASD [31, 32]. Studies repeatedly showed that patients with ASD exhibit slower reaction times [33] as well as more incorrect classifications of emotion assignments than typically developing subjects [34-36]. Moreover, the gaze at the eyes of others is associated with a higher rate of correct answers in emotion recognition and lower symptom severity [37]. Contrary, atypical brain activations during the presentation of faces with different emotions were associated with deficits in the processing of facial expressions [38]. Regarding sex differences, Kothari et al. [39] found impaired emotional processing in boys with ASD compared to girls with ASD, assuming that girls with ASD probably compensate their underlying deficits.

Here, a general framework is required to determine which cognitive and emotional processes are specifically deficient in males and females in ASD. Furthermore, valid measures linking behavior, psychopathology and neurophysiology need to be established [23].

Neurofeedback training as a new treatment option in $A S D$

Currently no standard treatment, such as cognitive behavioral therapy or psychopharmacological interventions target the core symptomatology of ASD or consider sex as a potential influencing factor for treatment outcome [40, 41].

Although biological approaches also do not consider sex as an influencing factor, they aim to change the biological basis of ASD for the purpose of symptom reduction. Regarding the biological basis of 
ASD, brain imaging studies reported diminished cortical excitability and reduced frontal brain activity related to impaired neural plasticity [42-44]. Parallel, resting state electroencephalography (EEG) studies demonstrated impairments in long-range connectivity between frontal lobe and other cortical regions, together with short-range overconnectivity [45-47]. The most consistent findings regarding abnormal frequency band activity in ASD is an overexpression of slow frequency bands, together with a decreased alpha band power $[45,48]$.

Therefore, a biological approach targeting exactly these seemingly impaired biological hubs seems to be a promising treatment strategy for ASD. One method enabling subjects to volitionally learn to change brain activity levels is electroencephalography (EEG)-based neurofeedback. In this self-regulation training method, brain waveforms are measured, analyzed and fed back in real time to the subject. Through this feedback (operant conditioning), the participants can learn special stimulus response patterns by altering their brain activity to a desired state. Successful symptom improvements after EEG neurofeedback training were reported in drug-resistant epilepsy [49], ADHD [50-53], criminal psychopathy [54] as well as in migraine [55].

The first case study about neurofeedback training in ASD was conducted by Cowan and Markham in 1994 [56] with an 8-year-old girl. Using frequency bands as feedback signal, the aim was to suppress the ratio of alpha and theta to beta EEG activity. It could be shown that after 21 neurofeedback sessions there was a decrease of autistic behavior and an increase of sustained attention. The changes were long-lasting as the follow-up after 2 years still showed behavior and attention scores within the normal range. Pineda et al. [57] found neurophysiological improvements, such as increased brain frequency coherence and normalization after neurofeedback training in ASD, whereas Koujizer et al. [58] showed a reduction of theta and delta power in $54 \%$ of the participants. In this study, ASD symptoms did not decline but the study participants showed improved cognitive flexibility. This finding is supported by a recent randomized clinical trial [59] showing that the attentional span and the social interaction skills improved in addition to the cognitive flexibility. Van Hoogdalem [60] described that neurofeedback studies in ASD predominantly recruited male participants and the study results were merely transferred to female patients.

Current literature provides evidence that males and females with ASD have different neurophenotypes [2], highlighting the need to explore how sex influences the effectiveness of neurobiologically based treatment modalities for individuals with ASD. To our knowledge, this is the first study looking at sex differences in outcome measures after a neurofeedback therapy in patients with ASD.

\section{Methods}

\section{Objective and hypotheses}

The present study is part of a larger clinical trial investigating neurofeedback therapy for adolescents with ASD, conducted by Konicar et al. [61]. The aim of the main study was to investigate changes in ASD core symptoms and psychopathological concomitant symptoms after slow cortical potential (SCP) neurofeedback therapy in male adolescents with ASD.

The current study aims to extend the findings of this larger clinical trial by conducting the same neurofeedback therapy as in the study mentioned above [61] but in an explanatory manner with female adolescents with ASD. Therefore, the main aim of this current study is to investigate potential sex differences in treatment outcome, i.e. differences regarding psychopathological concomitant symptoms, emotion recognition and cognitive flexibility.

Hence, we expect sex differences in adolescents with ASD regarding the improvements in psychopathological concomitant symptoms (i.e. primary endpoint), cognitive flexibility and emotion recognition (i.e. secondary endpoints) following the EEG neurofeedback training.

\section{Subjects}

Besides the data of the male sample [61], the additional initial female sample consisted of 10 girls with ASD. Due to the coronavirus disease 2019 (COVID-19) pandemic and the associated temporary suspension of scientific projects (in March 2020), the neurofeedback therapy of two female participants had to be discontinued. For the same reason, the planned start of the neurofeedback intervention for two further female subjects had to be cancelled. This resulted in a subsample of six female adolescents with ASD who were matched to six male adolescents with ASD according to age, IQ and the degree of ASD symptom severity. Therefore, a total of 12 right-handed study participants, including 6 female and 6 male adolescents with ASD, based on state-of-the-art diagnostic procedures (ADI-R [16]; ADOS-2 [11]) between 12 and 18 years old were included in this study. Participants with an IQ below 70 assessed with the Hamburg-Wechsler intelligence test for children (HAWIK IV [63]), severe head injuries or a severe mental and neurological illness in medical history (i.e., major axis I diagnosis of obsessive-compulsive disorder, psychosis, tics, Tourette syndrome, depression with acute suicidal tendencies, epilepsy) were excluded. Furthermore, study participation with simultaneous participation in other clinical trials or former experience with neurofeedback therapy was not allowed. Accompanying psychopharmacological, behavioral or educational therapy were permitted throughout the study but had to be kept constant during 4 weeks before and 
until the end of the study. Written informed consent was obtained from all participants and their parents or legal guardians before being enrolled. The study was approved by the Ethics Committee of the Medical University of Vienna in accordance with the Declaration of Helsinki. Subject recruitment and data collection was conducted at the ABC BRAIN LAB, located at the Department of Child and Adolescent Psychiatry at the Medical University of Vienna (Austria).

\section{Matching}

The data of the six female adolescents with ASD were matched to data of six male adolescents with ASD according to age, IQ and symptom severity according to their ASD scores via the total score of the social responsiveness score (SRS) prior to the intervention. Both groups of adolescents (male/female) received the same amount of neurofeedback training sessions and conducted exactly the same study procedure (pre/post measurements).

\section{Experimental design and SCP neurofeedback training procedure}

Premeasurements were conducted within 2 weeks before the neurofeedback intervention started. The participants received neurofeedback training twice a week over the course of 3 months for a total of 24 sessions. The post-surveys were conducted in the same manner as the pre-surveys. The therapeutic neurofeedback procedure is described in detail in Konicar et al. [61]. Brain activity was presented as a graphical object (e.g. fish) on the participants' screen and reinforced in accordance with prevailing learning theories [62]. One single trial lasted for $10 \mathrm{~s}$ : $2 \mathrm{~s}$ of baseline recording was followed by an $8 \mathrm{~s}$ active regulation phase. In total, 120 neurofeedback trials divided into 3 training blocks, were performed during each training session [61]. The neurofeedback training was divided into 2 training phases, each consisting of 12 sessions and a training break in between.

\section{Materials}

Psychological measures: co-occurring psychopathological symptoms

To capture concomitant psychopathological symptoms, a psychological self-report questionnaire, the German version of the youth self-report (YSR/11-18R [23]), was used as well as a parental version (child behavior checklist 6-18 revised; CBCL/6-18R, [23]). Both questionnaires comprised an internalizing problems subscale, an externalizing problems subscale, as well as a total score.
Behavioral measures: emotion recognition and cognitive flexibility

A. Measure of emotion recognition (via the Frankfurter Test und Training des Erkennens von fazialem Affekt, FEFA-2 [64]).

This computerized test reflects the ability to recognize six basic emotions (happiness, sadness, fear, anger, disgust, surprise) and neutral facial expression [65]. The task consists of 50 black and white photographs of adult faces (that differ in age, sex and ethnicity), which should be assigned to the correct emotion. Percentages of correct answers are recorded and analyzed.

B. Measure of cognitive flexibility via tests of attentional performance (TAP 2.3, [66]).

The capacity of cognitive flexibility as one aspect of executive functioning was measured with the subtest flexibility-condition verbal, a set-shifting task of the computer-based test battery TAP-version 2.3 designed for the assessment of various basic attention functions [66]. In this task, a letter and a number appear simultaneously to the left and right side of a fixation point on the screen. The participants are asked to respond alternately to the position of the target stimulus (the number or the letter) by pressing one of the two buttons corresponding to the respective position on the screen (left or right). Reaction time and error rates are recorded and analyzed.

\section{Statistical analysis}

Statistical analyses were performed using IBM SPSS Statistics (Version 27) for Windows. To examine sex differences regarding changes in psychological measures (self-report questionnaire YSR/1118R; caregiver-report questionnaire CBCL/6-18R), and behavioral measures (emotion recognition measured via FEFA-2; cognitive flexibility measured via TAP 2.3) across experimental groups, Welch's t-tests were used because of the unbalanced study design. The significance level of hypothesis testing was $5 \%$.

\section{Results}

\section{Subject matching}

No significant differences were found between the male versus the female sample of adolescents with ASD comparing age, IQ and SRS total score, as presented in Table 1.

\section{Sex differences in premeasures}

Analyses revealed significant sex differences in cooccurring psychopathological symptoms, assessed by the caregivers (CBCL) of the adolescents with ASD, before the intervention. 
Table 1 Matching characteristics at premeasurements

\begin{tabular}{|c|c|c|c|c|}
\hline \multirow[b]{2}{*}{ Variable } & \multirow{2}{*}{$\begin{array}{l}\text { Male }(n=6)^{\mathrm{a}} \\
\mathrm{M}(\mathrm{SD})\end{array}$} & \multirow{2}{*}{$\begin{array}{l}\text { Female }(n=6)^{\mathrm{a}} \\
\mathrm{M}(\mathrm{SD})\end{array}$} & \multicolumn{2}{|c|}{ Welch's statistics } \\
\hline & & & $t(d f)$ & $p$-value \\
\hline Age (years) & $14.33(1.51)$ & $14.83(2.04)$ & 0.48 (9.198) & 0.640 \\
\hline IQ & $104.00(13.80)$ & $101.60(25.01)$ & $-0.19(6.218)$ & 0.857 \\
\hline SRS total score & $91.33(24.60)$ & 96.17 (19.36) & 0.38 (9.478) & 0.714 \\
\hline $\begin{array}{l}\text { Results were co } \\
M \text { mean, } S D \text { sta } \\
\text { sive scale, df de } \\
\text { aFor the IQ data } \\
\text { analysis }\end{array}$ & idered as signif & cant at an alpha & evel of $p<0.05$ & $\begin{array}{l}\text { pon- } \\
\text { ching }\end{array}$ \\
\hline
\end{tabular}

Table 2 Subjective rating scales and behavioral measures at premeasurements

\begin{tabular}{llllll|} 
& Male $(n=6)$ & Female $(n=6)$ & \multicolumn{2}{l}{ Welch's statistics } \\
\hline Parameters & $\mathrm{M}(\mathrm{SD})$ & $\mathrm{M}(\mathrm{SD})$ & $\mathrm{t}(\mathrm{df})$ & $p$-value \\
\hline Total CBCL score & $58.33(14.26)$ & $78.67(5.47)$ & $3.26(6.437)$ & $0.016^{\mathrm{a}}$ \\
\hline Total YSR score $^{\mathrm{b}}$ & $72.17(24.00)$ & $65.80(23.68)$ & $-0.44(8.685)$ & 0.670 \\
\hline FEFA-2 & $0.79(0.05)$ & $0.77(0.08)$ & $-0.51(8.717)$ & 0.622 \\
\hline $\begin{array}{l}\text { TAP reaction } \\
\text { time }\end{array}$ & 765.84 & 769.78 & $0.06(9.944)$ & 0.954 \\
\hline TAP error rate & $7.3(4.08)$ & $5.5(3.15)$ & $-0.87(9.391)$ & 0.405 \\
\hline
\end{tabular}

$M$ means, $S D$ standard deviation, $C B C L$ child behavior checklist, $Y S R$ youth self report, FEFA Frankfurter Test und Training des Erkennens von fazialem Affekt, TAP test of attentional performance

aResults were considered as significant at an alpha level of $p<0.05$

${ }^{b}$ For the YSR/11-18R, data from $n=5$ female participants were included in statistical analysis, due to technical problems with YRS implementation

No group differences in female and male subjects were found regarding emotion recognition (FEFA-2), cognitive flexibility (TAP, set shifting task) or selfreported co-occurring psychopathological symptoms (YSR), as shown in Table 2.

\section{Sex differences in treatment outcome}

Behavioral measures: emotion recognition and cognitive flexibility

No sex differences regarding changes in the facial affect recognition test FEFA-2 [64] were found from before to after neurofeedback intervention, as presented in Table 3.

Furthermore, analyses also showed no sex differences in the changes in cognitive flexibility (TAP 2.3 [66]), neither in reaction times nor in the error rate from before to after neurofeedback intervention.
Table 3 illustrates that both groups of adolescents with ASD (male/female) performed slightly better in emotion recognition as well as in cognitive flexibility (faster behavioral reactions, less errors) after the neurofeedback intervention, compared to before neurofeedback.

\section{Psychological measures: co-occurring} psychopathological symptoms of ASD

The analysis did not reveal any significant sex differences regarding treatment outcome measures on the psychological level. Neither, pre-post-intervention changes measured via self-report questionnaires (YSR), nor measured via parental reports (CBCL) yielded sex differences concerning the changes of cooccurring psychopathological symptoms.

The indices of treatment outcome ( $\Delta$ delta values) in Table 4 illustrate that male adolescents with ASD experience greater improvements regarding externalizing problems, internalizing problems and total problems than female adolescents; however, these differences were not statistically significant (YSR). Although females with ASD reported a decrease of externalizing problems and total problems after the intervention, the internalizing score seemed to be unaffected or even very slightly increased after the intervention. Inspecting the data of the baseline measures Table 4 shows that male adolescents with ASD already reported slightly more externalizing and internalizing (as well as total) problems before the intervention than female adolescents.

Examining the descriptive data of the parental ratings of co-occurring psychopathological symptoms (measured via CBCL), a contrary picture compared to adolescents' self-ratings emerges. The caregivers of the female adolescents with ASD rated higher decreases in the CBCL total score after the neurofeedback intervention; however, the caregivers of the male adolescents with ASD evaluated the changes on the CBCL from pre to post differently than the caregivers of the females. Although they reported a decrease of internal and total problems after the neurofeedback intervention, externalizing problems did not change or even slightly increased after the intervention, as shown in Table 4.

Table 3 Treatment outcome ( $\Delta$ delta index) of behavioral measures

\begin{tabular}{|c|c|c|c|c|c|c|c|c|}
\hline \multirow{3}{*}{$\begin{array}{l}\text { Variable } \\
\text { Total FEFA2 }\end{array}$} & \multicolumn{3}{|l|}{ Males $(n=6)$} & \multicolumn{3}{|l|}{ Females $(n=6)$} & \multicolumn{2}{|c|}{ Welch's statistics } \\
\hline & \multirow{2}{*}{$\begin{array}{l}\text { Pre-measure- } \\
\text { ment, M (SD) } \\
0.79(0.05)\end{array}$} & \multirow{2}{*}{$\begin{array}{l}\text { Post-measure- } \\
\text { ment, M (SD) } \\
0.81(0.04)\end{array}$} & \multirow{2}{*}{$\begin{array}{l}\Delta \\
0.02(0.02)\end{array}$} & \multirow{2}{*}{$\begin{array}{l}\text { Pre-measure- } \\
\text { ment, M (SD) } \\
0.77(0.08)\end{array}$} & \multicolumn{2}{|c|}{$\begin{array}{l}\text { Post-measure- } \Delta \\
\text { ment, M (SD) }\end{array}$} & \multirow{2}{*}{$\begin{array}{l}t(d f) \\
0.21(5.559)\end{array}$} & \multirow{2}{*}{$\begin{array}{l}p \text {-value } \\
0.841\end{array}$} \\
\hline & & & & & $0.79(0.10)$ & $0.03(0.08)$ & & \\
\hline \multicolumn{9}{|c|}{ TAP 2.3: Flexibility } \\
\hline Reaction time & $765.84(119.00)$ & $672.21(119.63)$ & $\begin{array}{l}-93.63 \\
(98.16)\end{array}$ & $\begin{array}{l}769.78 \\
(110.31)\end{array}$ & $\begin{array}{l}649.17 \\
(68.52)\end{array}$ & $-120.62(127.11)$ & $-0.41(9.399)$ & 0.690 \\
\hline Error rate & $7.3(4.08)$ & $5.83(3.87)$ & $-1.50(7.40)$ & $5.5(3.15)$ & $5.17(4.4)$ & $-0.33(4.13)$ & $0.34(7.843)$ & 0.745 \\
\hline
\end{tabular}


Table 4 Treatment outcome ( $\Delta$ delta index) of psychological measures

\begin{tabular}{|c|c|c|c|c|c|c|c|c|}
\hline & \multicolumn{3}{|l|}{ Males $(n=6)$} & \multicolumn{3}{|c|}{ Females $(n=6)^{\mathrm{a}}$} & \multicolumn{2}{|c|}{ Welch's statistics } \\
\hline & $\begin{array}{l}\text { Pre-measure- } \\
\text { ment, M (SD) }\end{array}$ & $\begin{array}{l}\text { Post-measure- } \\
\text { ment, M (SD) }\end{array}$ & $\Delta$ & $\begin{array}{l}\text { Pre-measure- } \\
\text { ment, M (SD) }\end{array}$ & $\begin{array}{l}\text { Post-measure- } \\
\text { ment, M (SD) }\end{array}$ & $\Delta$ & $t(d f)$ & $p$-value \\
\hline \multicolumn{9}{|l|}{ YSR/11-18R } \\
\hline Ext. problems & $19.50(7.66)$ & 17.33 (7.34) & $-2.17(3.82)$ & $16.00(6.60)$ & $14.40(6.70)$ & $-1.60(2.07)$ & $0.313(7.926)$ & 0.763 \\
\hline Int. problems & $14.83(12.51)$ & $11.00(7.00)$ & $-3.83(6.00)$ & 14.20 (10.92) & 14.80 (10.99) & $0.60(1.19)$ & 1.69 (6.528) & 0.139 \\
\hline Total YSR & $72.17(24.00)$ & 60.33 (15.38) & $-11.83(13.59)$ & $65.80(23.68)$ & $64.40(30.28)$ & $-1.40(10.10)$ & $1.46(8.923)$ & 0.179 \\
\hline \multicolumn{9}{|l|}{ CBCL/6-18R } \\
\hline Ext. problems & $14.83(6.11)$ & $15.00(8.37)$ & $0.17(5.64)$ & $19.5(9.50)$ & $15.17(12.00)$ & $-4.33(6.50)$ & $-1.28(9.803)$ & 0.230 \\
\hline Int. problems & $13.83(6.50)$ & $7.83(4.10)$ & $-6.00(4.15)$ & 22.50 (6.32) & $16.83(6.91)$ & $-5.67(6.31)$ & 0.11 (8.637) & 0.916 \\
\hline Total CBCL & $58.33(14.26)$ & $41.83(17.56)$ & $-16.50(16.72)$ & 78.67 (5.47) & $56.17(25.50)$ & $-22.50(21.44)$ & $-0.54(9.440)$ & 0.601 \\
\hline
\end{tabular}

\section{Discussion}

The present study investigated sex differences regarding the effects of an intense neurofeedback training on emotion recognition abilities, cognitive flexibility and co-occurring psychopathological symptoms in male and female adolescents with ASD. A study including females with ASD seemed especially important as woman or girls are underrepresented in basic research and interventional treatment studies and specifically because of the underrepresentation in research in ASD.

Contrary to our expectations, analysis did not reveal any significant sex differences with respect to any treatment outcome measure used in our study. Neither delta values from pre to post regarding co-occurring psychopathological symptoms of ASD, nor delta values regarding cognitive flexibility or emotion recognition showed significant differences between male and female adolescents with ASD. Therefore, our findings do not correspond with a recent study about neurofeedback training on learning disorders [67] investigating 28 elementary school students with dyscalculia. Only in males could positive effects be evaluated after 20 sessions of beta/theta neurofeedback training.

Facing the different levels of measures, i.e. measures on the subjective psychological level (co-occurring psychopathological symptoms) versus measures on the behavioral level (emotion recognition, cognitive flexibility) of our study, an interesting picture emerged.

On one hand, the behavioral reactions in emotion recognition abilities are seemingly not influenced by the sex of the participant, with almost no measurable increase from pre to post for both male and female adolescents. Similarly, the behavioral data measuring cognitive flexibility also seem unrelated to the sex of the participants. Here, small improvements in the behavioral performances i.e. decreases in error rates and faster reaction times from pre to post could be registered for both sex, which is in line with the study of Kouijzer et al. [58]. Similar positive effects of neu- rofeedback on executive functions could be shown in children with ASD [31].

On the other hand, although not the pre-post-treatment change but the evaluation of co-occurring psychopathological symptoms of ASD seems to be related to the sex of the study participant. Significant sex differences were found at the time of premeasurement in the parental evaluations, as caregivers described significantly higher levels of burden (CBCL total score) for daughters than for sons with ASD, which is consistent with a study of Holtmann et al. [68].

Regarding the self-reported version of the same questionnaire (YSR), interestingly, the opposite picture emerged although this difference did not reach the level of significance (potentially due to the higher SD). Male adolescents with ASD rated their internalizing and externalizing problems on average as more severe than female adolescents with ASD.

Summing up on a descriptive level, it seems that boys with ASD rated their psychopathology as more severe than their caregivers, whereas the caregivers of girls with ASD rated the girls' psychopathologies as more severe than the girls with ASD themselves, which partly contradicts previous research by Pisula et al. [69]. One possible explanation for the fact that girls assess their psychopathological symptoms as less severe than their caregivers could be explained by the camouflage effect $[5,6]$, which is in line with previous research showing that females tend to hide their difficulties in social contact [70]. Another explanation would be that there is a sex-based bias regarding caregivers' expectations of their children as some authors described that caregivers generally expect higher levels of social interaction skills from daughters than from sons [71].

Regarding the tendency of co-occurring psychopathological symptoms of ASD to decrease after neurofeedback training, our results are consistent with previous studies. Similar to Mekkawy [59], reporting significant decreases in recurrent problem scores of the CBCL after neurofeedback training in children with ASD, our analysis showed decreases in the inter- 
nalizing and externalizing scale as well as in the total scores of the CBCL after neurofeedback training.

Notwithstanding, the current study has several limitations and cannot provide generalizable results because of its experimental design and exploratory character. Besides the small sample size due to challenging recruitment of females with ASD and the emergence of COVID-19 restrictions, also possible other influences on the results, such the strong overlap of ASD with ADHD could not be ruled out in this study. As sex differences in ADHD were reported in many studies [24, 29, 30], disentangling and differentiating of the potentially influencing, underlying components would be an interesting area for future research. Furthermore, the investigation of possible age-related sex differences in neurofeedback training as well as examining potential sex differences regarding long-term effects of neurofeedback training in ASD may be other interesting future research ventures.

\section{Conclusion}

The current study highlights the importance of measuring baseline data and treatment outcome on different levels, when aiming to investigate sex differences. Although the level of significance was not reached on the behavioral level as well as on the subjective psychological level, regarding changes in treatment outcome, the latter might potentially be more biased regarding sex differences in ASD. Especially, third party evaluators seem to rate the comorbid psychopathological symptoms differently related to the sex of the evaluated persons. If this is due to biased psychological rating scales (which do not portray the diverging sex-related clinical presentations of the disorder appropriately) or due to the already biased perspectives and expectations of the caregivers on characteristics and personal features of sex in general, is still an open question.

Nevertheless, the present study adds to the growing body of research on alternative and noninvasive treatment approaches for individuals with ASD, fulfilling the call [40] to close the gap of previous research and investigate potential sex differences in the field of neurofeedback therapy.

Considering the potential consequences of unnoticed sex differences in ASD treatment outcome research, our study sheds light on potential moderating factors on specific levels of assessment, which should be considered in future studies. In addition, the present study exemplifies the importance of recruiting female participants to overcome the dominance of studies with solely male subjects. Including larger sample sizes measured on different outcome levels would allow more accurate and specific interpretations and potential therapeutic adjustments related to the sex of the treated patient.
Acknowledgements We would like to thank the psychologists, psychiatrists and therapists, social workers and hospital staff of the Department of Child and Adolescent psychiatry of the Medical University of Vienna. We also want to thank the study participants who made this study possible. We also express special thanks to all co-workers for assisting in the data collection.

Funding This project was funded by the Austrian Science Fund (FWF): KLI600B27.

Funding Open access funding provided by Medical University of Vienna.

\section{Declarations}

Conflict of interest S.G. Werneck-Rohrer, T.M. Lindorfer, C. Waleew, J. Philipp, K. Prillinger and L. Konicar declare that they have no competing interests.

Ethical standards All procedures performed in studies involving human participants or on human tissue were in accordance with the ethical standards, have been approved by the Ethics Committee of the Medical University of Vienna, Austria and have therefore been performed in accordance with the 1964 Helsinki declaration and its later amendments or comparable ethical standards. All persons gave their informed consent prior to their inclusion in the study.

Open Access This article is licensed under a Creative Commons Attribution 4.0 International License, which permits use, sharing, adaptation, distribution and reproduction in any medium or format, as long as you give appropriate credit to the original author(s) and the source, provide a link to the Creative Commons licence, and indicate if changes were made. The images or other third party material in this article are included in the article's Creative Commons licence, unless indicated otherwise in a credit line to the material. If material is not included in the article's Creative Commons licence and your intended use is not permitted by statutory regulation or exceeds the permitted use, you will need to obtain permission directly from the copyright holder. To view a copy of this licence, visit http://creativecommons.org/licenses/by/4.0/.

\section{References}

1. Dilling H, Mombour W, Schmidt MH, Schulte-Markwort E, Remschmidt $\mathrm{H}$, Weltgesundheitsorganisation. Internationale Klassifikation psychischer Störungen. 10th ed. Göttingen: Hogrefe; 2015. unter Berücksichtigung der Änderungen entsprechend ICD-10-GM2015.

2. Lai M-C, Lombardo MV, Auyeung B, Chakrabarti B, BaronCohen S. Sex/Gender differences and autism: setting the scene for future research. JAm Acad Child Adolesc Psychiatry. 2015;54(1):11-24.

3. Hull L, Petrides KV, MandyW. The female autism phenotype and camouflaging: a narrative review. Rev J Autism Dev Disord. 2020;7(4):306-17.

4. Baron-Cohen S. The extreme male brain theory of autism. Trends Cogn Sci. 2002;6(6):248-54.

5. Tubío-Fungueiriño M, Cruz S, Sampaio A, Carracedo A, Fernández-Prieto M. Social camouflaging in females with autism spectrum disorder: a systematic review. J Autism Dev Disord. 2020;51(7):2190-9.

6. Hull L, Petrides KV, Allison C, Smith P, Baron-Cohen S, Lai M-C, et al. "Putting on my best normal": social 
camouflaging in adults with autism spectrum conditions. JAutism Dev Disord. 2017;47(8):2519-34.

7. Cola ML, Plate S, Yankowitz L, Petrulla V, Bateman L, Zampella CJ, et al. Sex differences in the first impressions made by girls and boys with autism. Mol Autism. 2020;11(1):49. https://doi.org/10.1186/s13229-020-00336-3.

8. Loomes R, Hull L, Mandy WPL. What is the male-to-female ratio in autism spectrum disorder? A systematic review and meta-analysis. J Am Acad Child Adolesc Psychiatry. 2017;56(6):466-74.

9. American Psychiatric Association. Diagnostisches und statistisches Manual psychischer Störungen DSM-5. Göttingen: Hogrefe; 2015. Deutsche Ausgabe, herausgegeben von P Falkai and UWittchen.

10. Baron-Cohen S, Wheelwhright S, Skinner R, Martin J, Clubley E. The autism-spectrum quotient (AQ): evidence from Asperger-Syndrome/high-functioning autism, males and females, scientists and mathematicians. J Autism Dev Disord. 2001;31(1):5-17.

11. Poustka L, Rühl D, Feineis-Matthews S, Poustka F, Hartung M, Bölte S. Diagnostische Beobachtungsskala für Autistische Störungen-2 (ADOS-2). Mannheim: Huber; 2015. Deutschsprachige Fassung der Autism Diagnostic Observation Schedule -2 von C. Lord, M. Rutter, P.C. DiLavore, S. Risi, K. Gotham und S.L. Bishop (Module 1-4) und C. Lord, R.J. Luyster, K. Gotham und W. Guthrie (KleinkindModul): Technical Manual.

12. RynkiewA, ŁuckaI. Autism spectrum disorder (ASD) in girls. Co-occurring psychopathology. Sex differences in clinical manifestation. Psychiatr Pol. 2018;52(4):629-39.

13. Frazier TW, Georgiades S, Bishop SL, Hardan AY. Behavioral and cognitive characteristics of females and males with autism in the Simons Simplex Collection. J Am Acad Child Adolesc Psychiatry. 2014;53(3):329-40.

14. Hartley SL, Sikora DM. Sex differences in Autism Spectrum Disorder: an examination of developmental functioning, autistic symptoms, and coexisting behavior problems in toddlers. JAutism Dev Disord. 2009;39(12):1715-22.

15. Supekar K, Menon V. Sex differences in strucutral organization of motor systems and their dissociable link with repetitive/restricted behaviors in children with autism. Mol Autism. 2015;6:50. https://doi.org/10.1186/s13229-0150042-z.

16. Bölte S, Rühl D, Schmötzer G, Poustka F. Diagnostisches Interview für Autismus-Revidiert (ADI-R). Deutsche Fassung desAutism Diagnostic Interview-Revised von Michael Rutter, Ann Le Couteur und Catherine Lord: Technical Manual. Mannheim: Huber; 2006.

17. Bargiela S, Steward R, Mandy W. The experience of latediagnosed women with autism spectrum conditions: an investigation of the female autism phenotype. J Autism Dev Disord. 2016;46(19):3281-94.

18. Posserud MB, Lundervold AJ, Gillberg C. Autistic features in a total population of 7-9-year-old children assessed by the ASSQ (Autism Spectrum Screening Questionnaire). J Child Psychol PsychiatryAllied Discip. 2006;47(2):167-75.

19. Giarelli E, Wiggins LD, Rice CE, Levy SE, Kirby RS, PintoMartin J, et al. Sex differences in the evaluation and diagnosis of autism spectrum disorders among children. Disabil Health J.2010;3(2):107-16.

20. Pellicano E, Dinsmore A, Charman T. What should autism research focus upon? Community views and priorities from the United Kingdom. Autism. 2014;18(7):756-70.

21. Dwarzynski K, Ronald A, Bolton P, Happe F. How different are girls and boys about and below the diagnostic threshold of autism spectrum disorders? J Am Acad Child Adolesc Psychiatry. 2012;51(8):788-97.
22. MiyakeA,Firedman NP,Emerson MJ, WitzkiAH,HowerterA, Wager TD. The unity and diversity of executive functions and their contributions to complex "frontal lobe" tasks: a latent variable analysis. Cogn Psychol. 2000;41(1):49-100.

23. Guerts HM, CorbettB, Solomon M. The paradox of cognitive flexibility in autism. Trends Cogn Sci. 2009;13(2):74-82.

24. WillcutEG, DoyleAE, NiggJT, FaraoneSV,Pennington BF.Validity of the executive function theory of attention-deficit/ hyperactivity disorder: a meta-analysis review. Biol Psychiatry. 2005;57:1336-46.

25. Demetriou EA, Lampit A, Naismith SL, et al. Autism spectrum disorders: a meta-analysis of executiv function. Mol Psychiatry. 2018;23:1198-204.

26. Heaton RK. Wisconsin card sorting test manual. Odessa: Psychological Assessment Resources; 1981.

27. Hull L, Mandy W, Petrides KV. Behavioral and cognitive sex/gender differences in autism spectrum condition and typically developing males and females. Autism. 2017;21(6):706-27.

28. Shafritz KM, Dichter GS, Baranek GT, Belger A. The neural circuitry mediating shifts in behavioral response and cognitive set in autism. Biol Psychiatry. 2008;63:974-80.

29. ArnettAB, Pennington BF, WillcuttEG, DeFries JC, Olson RK. Sex differences in ADHD symptom severity. JChild Psychol Psychiatry. 2015;56(6):632-9.

30. Baron-Cohan S, Spitz A, Cross P. Do children with autism recognise surpise? A research note. Cogn Emot. 1993;7:507-16.

31. Lozier LM, Vanmeter JW, Marsh AA. Impairments in facial affect recognition associated with autism spectrum disorders: a meta-analysis. Dev Psychopathol. 2014;2014:1-13.

32. Carbonneau ML, Demers M, Bigras M, et al. Meta-analysis of sex differences in ADHD symptoms and associated cognitive deficits. JAtten Disord. 2021;25(12):1646-56.

33. Fink E, de Rosnay M, Wierda M, Koot HM, Begeer S. Brief report: accuracy and response time for the recognition of facial emotions in a large sample of children with Autism Spectrum Disorders. JAutism Dev Disord. 2014;44:2363-8.

34. Webster PJ, Wang S, Li X. Review: Posed vs. genuine facial emotion recognition and expression in autism and implications for intervention. Front Psychol. 2021; https:// doi.org/10.3389/fpsyg.2021.653112.

35. Kuusiko S, Haapsamo H, Jansson-Verkasalo E, Hurtig T, Mattila M-L, Ebeling $\mathrm{H}$, et al. Emotion recognition in children and adolescents with autism spectrum disorders. JAutism Dev Disord. 2009;39(6):938-45.

36. Fridenson-Hayo S, Berggren S, Lassalle A, Tal S, Pigat D, Bölte $S$, et al. Basic and complex emotion recognition in children with autism: cross-cultural findings. Mol Autism. 2016;7:52. https://doi.org/10.1186/s13229-016-0113-9.

37. Bal E, Harden E, Lamb D, Van Hecke AV, Denver JW, Porges SW. Emotion recognition in children with autism spectrum disorders: relations to eye gaze and autonomic state. JAutism Dev Disord. 2010;40(3):358-70.

38. Black MH, Chen NTM, Iyer KK, Lipp OV, Bölte S, Falkmer $\mathrm{M}$, et al. Mechanisms of facial emotion recognition in autism spectrum disorders: insights from eye tracking and electroencephalography. Neurosci Biobehav Rev. 2017;80:488-515.

39. KothariR, Skuse D, WakefieldJ, Micali N. Gender differences in the relationship between social communication and emotion recognition. J Am Acad Child Adolesc Psychiatry. 2013;52(11):1148-57.

40. Lerner MD, White SW, McPartland JC. Mechanisms of change in psychosocial interventions for autism spectrum disorders. Dialogues Clin Neurosci. 2012;14(3):307-18. 
41. Green RM, Travers AM, Howe Y, McDougle CJ. Women and autism spectrum disorder: diagnosis and implications for treatment of adolescents and adults. Curr Psychiatry Rep. 2019;21(4):22. https://doi.org/10.1007/s11920-019-10063.

42. Parellada M, Penzol MJ, Pina L, Moreno C, GonzálezVioque E, Zalsman G, et al. The neurobiology of autism spectrum disorders. Eur Psychiatr. 2014;29:11-9.

43. Ecker C, Bookheimer SY, Murphy GM. Neuroimaging in autism spectrum disorder: brain structure and function across thelifespan. Lancet Neurol. 2015;14(11):1121-34.

44. Hoofs V, Princen MM, Poljac E, Stolk A, Poljac E. Task switching in autism: an EEG study on intentions and actions. Neuropsychologia. 2018;117:398-407.https://doi. org/10.1016/j.neuropsychologia.2018.07.008.

45. Wang J, Barstein J, Ethridge LE, Mosconi MW, Takarae Y, Sweeney JA. Resting state EEG abnormalities in autism spectrum disorders. J Neurodev Disord. 2013;5:24. https:// doi.org/10.1186/1866-1955-5-24.

46. Zhou T, Kang J, Cong F, Li DX. Early childhood developmental functional connectivity of autistic brains with non-negative matrix factorization. Neuroimage. 2020;26:102251. https://doi.org/10.1016/j.nicl.2020.102251.

47. Coben R, Clarke AR, Hudspeth W, Barry RJ. EEG power and coherence in autistic spectrum disorder. Clin Neurophysiol. 2008;119(5):1002-9.

48. Mash LE, Keehn B, Linke AC, Liu TT, Helm JL, Haist F, et al. Atypical relationships between spontaneous EEG and fMRI activity in Autism. Brain Connect. 2020;10:18-28. https:// doi.org/10.1089/brain.2019.069.

49. Strehl U, BirkleSM, Wörz S, Kotchoubey B. Sustained reduction of seizures in patients with intractable epilepsy after self-regulation training of slow cortical potentials-years after. Front Hum Neurosci. 2014;8:604.

50. Arns M, Heinrich H, Strehl U. Evaluation of neurofeedback in ADHD: The long and winding road. Biol Psychol. 2014; https://doi.org/10.1016/j.biopsycho.2013.11.013.

51. Mayer K, Wyckoff SN, Strehl U. One size fits all? Slow cortical potentials neurofeedback: a review. J Atten Disord. 2013;17(5):393-409. https://doi.org/10.1177/ 1087054712468053.

52. Strehl U, Aggensteiner P, Wachtlin D, etal. Neurofeedback of slow cortical potentials in children with attention-deficit/ hyperactivity disorder: a multicenter randomized trial controlling for unspecific effects. Front Hum Neurosci. 2017; https://doi.org/10.3389/fnhum.2017.00135.

53. Heinrich H, Gevensleben H, Strehl U. Annotation: Neurofeedback-Train your brain to train behaviour. J Child Psychol Psychiatry Allied Discip. 2007;48(1):3-16. https:// doi.org/10.1111/j.1469-7610.2006.01665.x.

54. Konicar L, Veit R, Eisenbarth H, Barth B, Tonin P, Strehl U, et al. Brain self-regulation in criminal psychopaths. Sci Rep. 2015;5:Article 9426.

55. Siniatchkin M, Hierundar A, Kropp P, Kuhnert R, et al. Selfregulation of slow cortical potentials in children with migraine: an exploratory study. Appl Psychophysiol Biofeedback. 2000;25:13-32.

56. Cowan J, Markham L. EEG biofeedback for the attention problems of autism. In: Annual Meeting of the Association for applied Psychophysiology and Biofeedback. 1994. pp. 12-3.
57. Pineda JA, Brang D, Hecht E, et al. Positive behavioral and electrophysiological changes following neurofeedback training in children with autism. Res Autism Spectr Disord. 2008;2(3):557-81.

58. Kouijzer MEJ, Van Schie HT, Gerrits BJL, Buitelaar JK, de Moor JMH. Is EEG-biofeedback an effective treatment in autism spectrum disorders? A randomized controlled trial. Appl Psychophysiol Biofeedback. 2013;38(1):17-28.

59. Mekkawy L. Efficacy of neurofeedback as a treatment modality for children in the autistic spectrum. Bull Natl Res Cent. 2021;45(1):45. https:// doi.org/10.1186/s42269-02100501-5.

60. Van Hoogdalem LE, Feijs HME, Bramer WM, Ismail SY, Van Dongen JDM. The effectiveness of neurofeedback therapy as an alternative treatment for autism spectrum disorders in children: a systematic review. J Psychophysiol. 2020;35(2):102-15.

61. Konicar L, Radev S, Prillinger K, Klöbl M, Diehm R, Birbaumer N, et al. Volitional modification of brain activity in adolescents with autism spectrum disorder: a bayesian analysis of slow cortical potential neurofeedback. Neuroimage Clin. 2021;29:102557. https://doi.org/10.1016/j. nicl.2021.102557.

62. Strehl U, editor. Neurofeedback: Theoretische Grundlagen - Praktisches Vorgehen - Wissenschaftliche Evidenz. Stuttgart: Kohlhammer;2013.

63. Petermann F, Petermann U. Hamburg-Wechsler-Intelligenztest für Kinder-IV. 2nd ed. Mannheim: Huber; 2008. Technical manua.

64. Bölte S, Feineis-Matthews S, Leber S, Dierks T, Hubl D, Poustka F. The development and evaluation of a computerbased program to test and to teach the recognition of facial affect. Int JCircumpolar Health. 2002;61 (Suppl. 2):61-8.

65. Ekman P, Friesen WV. Constants across cultures in the face and emotion. J Pers Soc Psychol. 1971;17(2):124-9.

66. Zimmermann P, Fimm B. Testbatterie zur Aufmerksamkeitsprüfung Version 2.3 [Battery of tests for assessing attention]. 2012. Psytest.

67. Hashemian P, Hashemian P. Effectiveness of neuro-feedback on mathematics disorder. J Psychiatry. 2015; https:// doi.org/10.4172/2378-5756.1000243.

68. Holtmann M, Bölte S, Poustka F. Autism spectrum disorders: sex differences in autistic behaviour domains and coexisting psychopathology. Dev Med Child Neurol. 2007;49(5):361-6.

69. Pisula E, Pudło M, Słowińska M, Kawa R, Strząska M, Banasiak A, et al. Behavioral and emotional problems in high-functioning girls and boys with autism spectrum disorders: Parents' reports and adolescents' self-reports. Autism. 2017;21(6):738-48.

70. Allely CS. Understanding and recognising the female phenotype of autism spectrum disorder and the "camouflage" hypothesis: a systematic PRISMA review. Adv Autism. 2019;5(1):14-37.

71. Bitsika V, Sharpley CF. Effects of diagnostic severity upon sex differences in behavioural profiles of young males and females with autism spectrum disorder. J Autism Dev Disord. 2019;49(11):4429-40.

Publisher's Note Springer Nature remains neutral with regard to jurisdictional claims in published maps and institutional affiliations. 